\title{
Effects of Physiochemical Properties of Nano-Clays on the Removal of Heavy Metals from Acid Mine Drainage
}

\author{
S.P. Gumede and P. Musonge
}

\begin{abstract}
The presence of heavy metals rich acid mine drainage (AMD) in some parts of South Africa pose health risks to humans and other living organisms owing to the toxic nature of heavy metals. The adsorption process has been recommended for the treatment of acid mine drainage (AMD) over the conventional processes because it is cheaper to operate, efficient and has good metal recovery efficiency. Adsorption capacity is mostly influenced by the surface properties such as porosity, functional groups, and the number of active sites. This study aims to establish changes to the adsorbents structure following adsorption of $\mathrm{Fe}$ (II) and $\mathrm{Mn}$ (II) and identifying the mechanism responsible for the adsorption of heavy metals into the surfactant modified bentonite (MB) and $\mathrm{Mg}$-Al hydrotalcite clay (HT) by characterizing the adsorbents before and after adsorption. The adsorbents were characterized using Fourier-transform infrared spectroscopy (FTIR), X-ray diffraction (XRD), Brunauer-Emmett-Teller (BET) and Scanning electron microscope (SEM). The change in peak intensity from FTIR indicates that the functional groups were responsible for adsorption. The analysis of the BET show that, HT has a high surface area compared to MB which may have contributed to high adsorption efficiency on HT. SEM/EDS proves that the structure of MB was amorphous and HT was crystalline and an increase in Fe (II) composition after adsorption proves that indeed the metal was removed by the adsorption process.
\end{abstract}

Keywords - Adsorption, acid mine drainage, manganese, Iron.

\section{INTRODUCTION}

Many industrial processes generate wastewater that is detrimental to the environment and human life. However, there seems to be a consensus that Acid Mine Drainage (AMD) is the main critical source of pollutant for surface and groundwater in mining regions globally. AMD is generated when sulfide-bearing material such as pyrite that react with oxygen and water [1].It is characterized as having low $\mathrm{pH}$, high specific conductivity, high concentrations of heavy metals [2]. Acid mine drainage is often released to streams and lakes that are used by human, plants, and animals for consumption. AMD contains heavy metal contaminants which are not biodegradable and thus tend to accumulate in living organisms, causing various diseases and disorders [3]. Concentrations of heavy metals in AMD vary significantly based on the source.

Manuscript received September 30, 2020.This work was supported in part by the National Research Fund under Grant UID 105235

S.P. Gumede is with the Durban University of Technology, Institute of Systems Science, South Africa.

P. Musonge is with Durban University of Technology, Institute of Systems Science, South Africa.
Iron and manganese are frequently present from coal and metal mines water drainage in high concentration [4]

There have been many different treatment processes developed to treat the effluents from mines. The processes include chemical precipitation, membrane filtration, ion exchange, carbon adsorption and co-precipitation/adsorption. The most common treatment method of acid mine drainage has been neutralization by using chemicals such as, calcium carbonate, hydrated lime, caustic soda, and soda ash which results in the production of voluminous amounts of sludge with solid content of 5\% and this sludge disposal represents a further environmental problem and additional cost. This high cost of conventional clean up technologies has produced economic pressure and has caused water/wastewater professionals to search for creative, cost effective and environmentally safe AMD treatment technologies[5].

Adsorption has been found to be an effective and economic method with high potential for the removal, recovery and recycling of metals from wastewater [6]. Adsorption is a physical treatment process which removes contaminants such as heavy metals by mass transfer through its adsorbent which has oppositely charge binding sites for the contaminants to latch on [7] [8]. Several researchers have concluded that heavy metal ions can be removed through precipitation of metal hydroxides, isomorphic substitution and chelation with functional ligand [9], [10].

The adsorption of heavy metal ions is associated with the formation of anion-metal complexes and hydroxide precipitation on surfaces through chemical bonding with the hydroxyl groups of clay [11]. The process of chemical bonding with hydroxyl group is called specific adsorption. Functional surface groups can be silanol groups, inorganic hydroxyl groups, or organic functional groups. Specific adsorption is based upon adsorption reactions at OH-groups at the clay surfaces and edges, which are negatively charged at high $\mathrm{pH}$. The adsorbing cation bonds directly by an inner sphere mechanism to atoms at the surface. As a consequence, the properties of the surface and the nature of the metal constituting the adsorption site influence the tendency for adsorption [12]. It will be of benefit to understand the sorption mechanisms and to develop new technologies for water treatment to investigate the sorption of metal cations on clay.

Clays and their modified forms have recently received wide 
attention for use as adsorbents of metal ions from aqueous medium because of their easy availability [13]. In addition nanomaterials, used as adsorbents to remove heavy metal ions from wastewater, have received significant attention owing to their high specific surface area [14], which make nano-clays the most promising adsorbent. Clays may be divided into two broad groups: cationic clays widespread in nature, and anionic clays, rarer in nature but relatively simple and inexpensive to synthesize.

Layered double hydroxides (LDHs in short), also known as hydrotalcite-like compounds or anionic clays are a large group of natural and synthetic layered materials[10]. Synthetic clays may have advantages over natural clay because variables such as purity, composition, reproducibility can be often controlled better than when using natural clay specimens, which, among other drawbacks, typically contain impurities [15]. They are perfect material for adsorption with large surface area per unit of mass, large porosity, etc. i.e. they satisfy all the requisite properties of adsorption[16]. A study on the removal of halides $\left(\mathrm{F}-, \mathrm{Cl}^{-}, \mathrm{Br}^{-}, \mathrm{I}^{-}\right)$and oxyanions $\left(\mathrm{NO} 3-, \mathrm{SO} 42^{-}, \mathrm{PO} 43^{-}\right.$, AsO4 3-) and heavy metals on LDH has been performed [17] but there is a need for an extensive study on the adsorption mechanism responsible for the removal of heavy metals.

Clays may be modified by either acid or with surfactants to alter the surface properties of the swelling clays in order to improve the sorption ability [18]. Previous studies have investigated the use of organo-clays, which are clay particles modified with organic cations, to improve the adsorption ability of organic contaminants. Organo-clay is often prepared by modifying natural clay mineral with quaternary ammonium surfactant [19].

The main aim of this study was to investigate the adsorption mechanism responsible for the removal of Fe (II) and Mn (II) from AMD using bentonite clay modified with Arquad surfactant and synthetic hydrotalcite clays. The objective was to determine the change in physicochemical properties of clays by performing physical and chemical characterization of the adsorbents before and after adsorption of the heavy metals using relevant analytical techniques (SEM, XRF, XRD, FTIR and BET)..

\section{METHODS AND MATERIALS}

\section{A. Adsorbent preparation and characterization}

Both the modified bentonite and hydrotalcite samples used in this study were donated by the Council for Scientific and Industrial Research (CSIR). The materials were produced in the CSIR's Nanomaterials Industrial Development Facility (NIDF) South Africa. Arquad 2HT-75 was used as a surfactant to modify $\mathrm{Ca}$ based bentonite at a ratio of 2:1 for the removal of manganese and iron. Arquad is one of the commonly used surfactants when modifying clays. It is traded as Arquad 2HT-75 and its composition is as follows: di (hydrogenated tallow) dimethyl ammonium chloride with 2-propanol and water.

\section{B. Adsorption experiment}

The adsorption experiments were carried out by synthesizing AMD with $\mathrm{Fe}$ (II) and $\mathrm{Mn}$ (II) from $\mathrm{FeSO}_{4} \cdot 7 \mathrm{H}_{2} \mathrm{O}$ and $\mathrm{MnSO}_{4} \cdot \mathrm{H}_{2} \mathrm{O}$. The concentration of $200 \mathrm{ppm}$ and $20 \mathrm{ppm}$ for $\mathrm{Fe}$ (II) and $\mathrm{Mn}$ (II) was prepared by dissolving $1 \mathrm{~g}$ of $\mathrm{FeSO}_{4} \cdot 7 \mathrm{H}_{2} \mathrm{O}$ and 0,062 of $\mathrm{MnSO}_{4} \cdot \mathrm{H}_{2} \mathrm{O}$ respectively in 1 litre of di-ionized water. $\mathrm{H}_{2} \mathrm{SO}_{4}$ was also added to obtain $\mathrm{pH}$ of 2 to mimic the $\mathrm{pH}$ of AMD. One gram of the adsorbent was added in a $50 \mathrm{ml}$ solution of a synthesized AMD at a pH of 2 and shaken in a Thermostatic water bath shaker at a temperature of $25^{\circ} \mathrm{C}$ for 24 $\mathrm{h}$ at a fixed speed of $150 \mathrm{rpm}$. After this period, the solution was filtered using Whatman grade 5 filter paper. The adsorbents were air-dried then taken for characterization.

\section{Characterization techniques}

$\mathrm{X}$-ray diffraction (XRD) measurements were obtained using a Bruker multipurpose powder diffractometer (D8 Advance), powered with $40 \mathrm{kV}$, current of $40 \mathrm{~mA}$, and irradiation $\mathrm{Cu} \mathrm{K \sigma}$ $(\lambda=1.5406 \mathrm{~nm})$. FTIR spectra were recorded using Spectrometer Pelkin Elmer, Frontier model over the wavelength range of $4000-400 \mathrm{~cm}-1$. Surface area and porosity were measured using a TriStar $3000 \mathrm{~V} 6.08 \mathrm{~A}$. The Nova NanoSEM scanning electron microscope with EDT detector and TLD detector was used to determine morphology and elementary composition of the adsorbent materials.

\section{RESULTS AND DISCUSSION}

\section{A. $X$-ray diffraction $(X R D)$}

The XRD patterns enable the interpretation of basal spacing (d-spacing) of clay before and after adsorption of metals and give some indications of any change in crystallographic structure. The adsorbents were analyzed after adsorption to investigate if heavy metals intercalated within clay sheets. The change in cationic composition after adsorption is an indication of adsorption taking place in clay. This change may be seen from the change in peak intensity. The peaks become broad and their intensity decreases depending on the size of the metal being adsorbed [20]. Figure 1 and 3 show the XRD patterns of hydrotalcite and modified bentonite, respectively. 


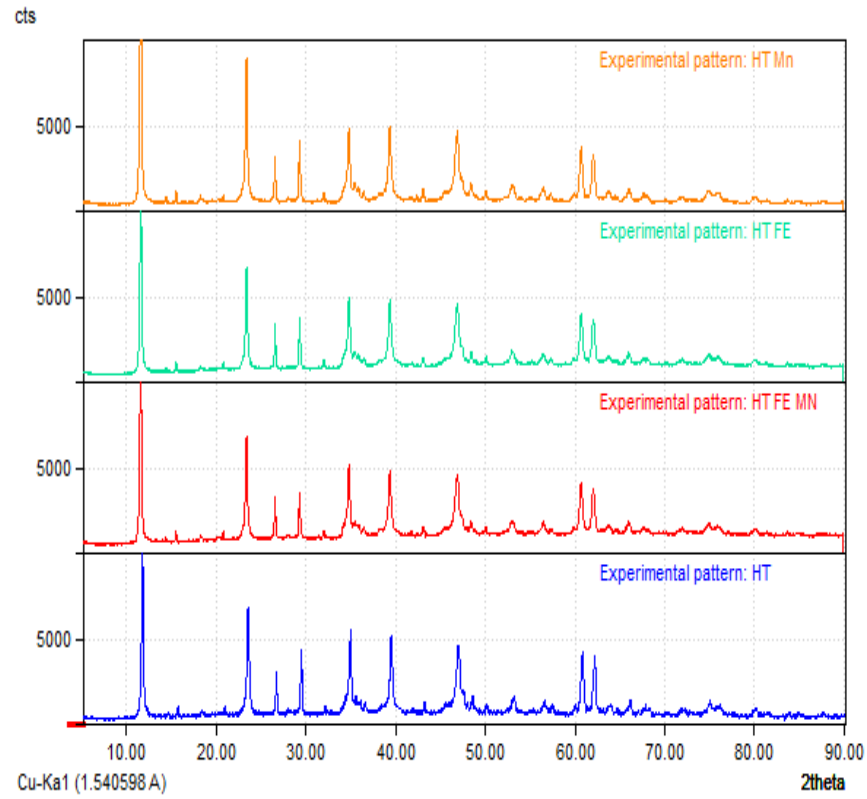

Fig. 1: XRD for hydrotalcite before and after adsorption of Fe with $\mathrm{Mn}$, adsorption of $\mathrm{Fe}$ and adsorption of $\mathrm{Mn}$.

Figure 1 shows the XRD graph for hydrotalcite before and after adsorption of singular Fe and $\mathrm{Mn}$ and the binary mixture of the two. Experimental pattern HT shows the XRD pattern for the raw hydrotalcite (before adsorption), experimental pattern HT FE MN shows the XRD pattern after the adsorption of $\mathrm{Fe}(\mathrm{II})$ and $\mathrm{Mn}(\mathrm{II})$, experimental pattern HT FE shows the XRD pattern after the adsorption of $\mathrm{Fe}(\mathrm{II})$ and experimental pattern HT MN shows the XRD pattern after the adsorption of $\mathrm{Mn}(\mathrm{II})$. The X-ray Diffraction (XRD) image for hydrotalcite shows peaks at $11.73,23.68,35$, and 39.42 which resemble typical peaks for layered double hydroxide. The sharpest diffraction peak for the (003), (006), and (009) planes proves that it had the best crystallinity and are essentially maintained after adsorption. The peak at $11.73^{\circ} 2$ ? for all samples of hydrotalcite was attributed to the reflections from (003) of crystallographic planes [20]. This peak is also described as a characteristic of divalent cations occupying the interlayer sites, see figure 2 for more description of the peak [21].

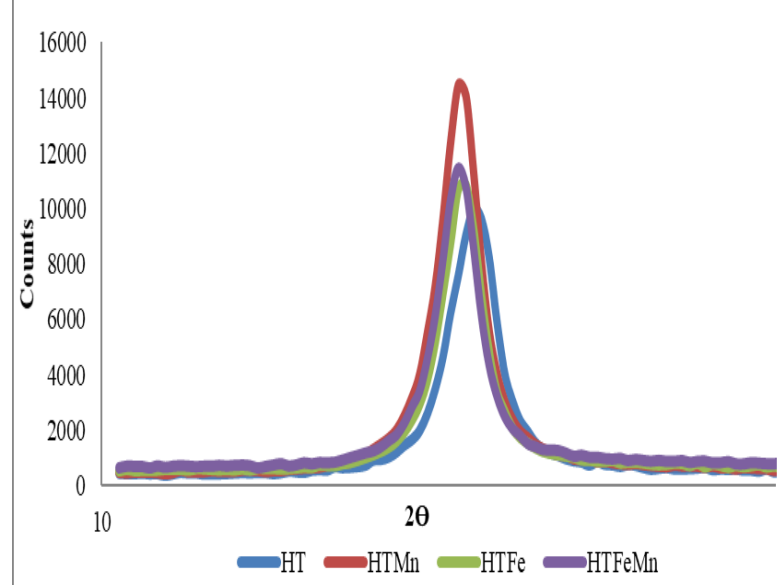

Fig. 2: High resolution diffraction peak from Figure 1 at $11.732 \theta$ before adsorption and after adsorption of $\mathrm{Fe}$ with $\mathrm{Mn}$, adsorption of $\mathrm{Fe}$ and adsorption of Mn.
Figure 2 shows the change in intensity of the peak at $11.732 \theta$ . HT shows the peak before adsorption at 8563, HT Mn shows the peak after adsorption of Mn (II) at 14441, HT Fe shows the peak after adsorption of Fe at 10773 and HT FeMn shows the peak after adsorption of $\mathrm{Fe}(\mathrm{II})$ and $\mathrm{Mn}$ (II) at 11483 . The intensity at peak 11.73 slightly shifted to lower $2 \theta$ values, indicating a slightly larger interlayer space. This indicates that $\mathrm{Fe}^{2+}$ and $\mathrm{Mn}^{2+}$ ions were intercalated into the HT via isomorphic substitution with $\mathrm{Mg}^{2+}$. During isomorphic substitution, the gallery height expands to fit the larger ionic size metals [22]. $\mathrm{Mn}^{2+}$ has ionic radii of 0.083 and $\mathrm{Fe}$ has the ionic radii of $0.078 \mathrm{~nm}$ whereas the substituent $\left(\mathrm{Mg}^{2+}\right)$ has the ionic radii of 0.066 . This may explain the peak expansion at $11.732 \theta$. Yue, X., et al.[22]obtained similar results using Cl-LDH for the adsorption of $\mathrm{Cu}^{2+}$ [22] .

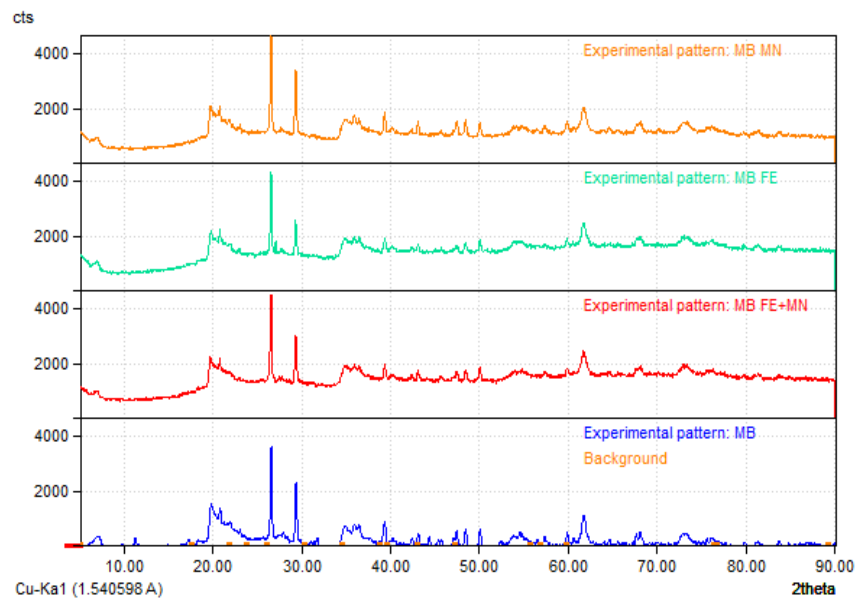

Fig. 3: XRD for modified bentonite before and after adsorption of Fe with $\mathrm{Mn}$, adsorption of $\mathrm{Fe}$ and adsorption of $\mathrm{Mn}$

Figure 3 shows the XRD image for modified bentonite before and after the adsorption of singular Fe and $\mathrm{Mn}$ and the binary mixture of Fe and Mn. Experimental pattern MB shows the XRD pattern for MB (before adsorption), experimental pattern MB FE+MN shows the XRD pattern after the adsorption of $\mathrm{Fe}(\mathrm{II})$ and $\mathrm{Mn}$ (II), experimental pattern MB FE shows the XRD pattern after the adsorption of $\mathrm{Fe}(\mathrm{II})$ and experimental pattern MB MN shows the XRD pattern after the adsorption of $\mathrm{Mn}$ (II) .The XRD pattern of modified bentonite show poor crystallinity, broad and less intense peaks due to the presence of layers of surfactant, or an irregular stacking of surfactant layers and thus the structure of the clay becomes amorphous to XRD. The X-ray diffractometer of modified bentonite samples showed that the main constituent was quartz with moderate to small amounts of some other minerals.

\section{B. FTIR analysis}

The FTIR analysis was utilized to determine the functional groups (Table 1) on the surface of clay responsible for adsorption. Comparing the FTIR spectra before and after adsorption as shown in figure 4 , there was a slight band shift and $\%$ transmittance increase suggesting a decrease in intensity. 


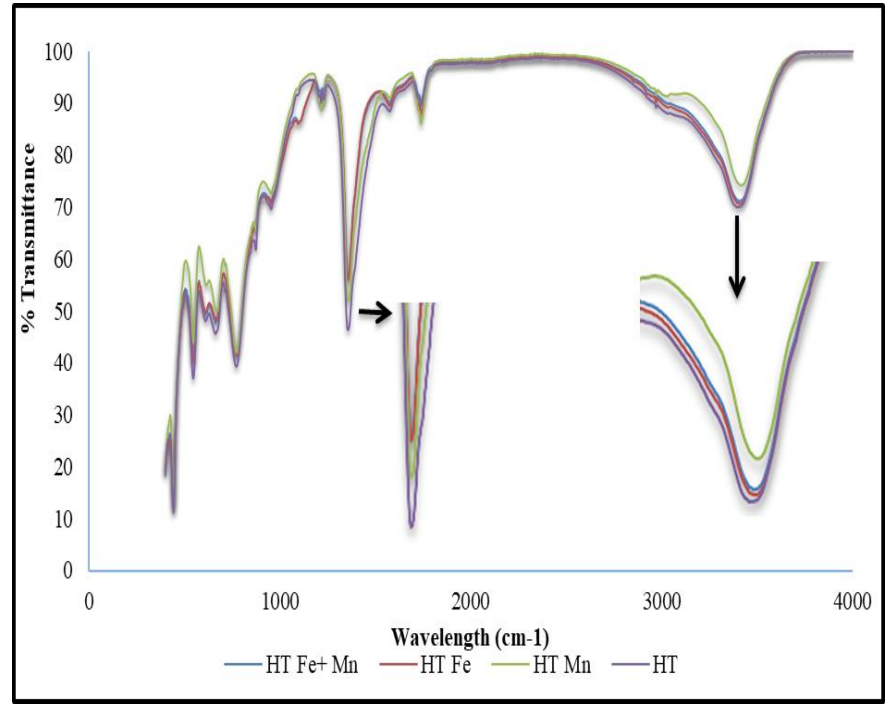

Fig. 4: FTIR for hydrotalcite before adsorption and after adsorption of $\mathrm{Fe}$ (II) $+\mathrm{Mn}$ (II), adsorption of Fe (II) and adsorption of Mn (II)

TABLE I: FUNCTIONAL GROUPS FOUND IN HYDROTALCITE AT DIFFERENT WAVELENGTH

\begin{tabular}{ll}
\hline Functional group & ${\text { Wavelength } \mathrm{cm}^{-1}}^{-1}$ \\
\hline O-H for AlOH, SiOH & 3420 \\
$\mathrm{H}-0-\mathrm{H}$ & 1740 \\
$\mathrm{CO}_{3}^{2-}$ & 1363 \\
$\mathrm{Si}-0$ quartz & 770 \\
Mg-O-Al,Si-O-Al stretching & 548 \\
Si-O-Si bending & 442 \\
\hline
\end{tabular}

In Figure.4,HT shows the FTIR pattern for the raw hydrotalcite (before adsorption), HT Fe Mn shows the FTIR pattern after the adsorption of $\mathrm{Fe}(\mathrm{II})$ and $\mathrm{Mn}$ (II), HT Fe shows the FTIR pattern after the adsorption of Fe(II) and HT Mn shows the FTIR pattern after the adsorption of Mn(II). The spectrum displayed an intense broad band at $3420 \mathrm{~cm}^{-1}$, which contributed to the stretching vibration of structural $\mathrm{O}-\mathrm{H}$ groups hydrogen bonded with inter-lamellar water or $\mathrm{O}-\mathrm{H}$ groups in adjacent layers. Another band at $1740 \mathrm{~cm}^{-1}$ was due to the bending vibration of $\mathrm{H}-\mathrm{O}-\mathrm{H}$ and it should be assigned to the adsorbed water molecule in the interlayer. An intense absorption bands at about $1363 \mathrm{~cm}^{-1}$ and at $680 \mathrm{~cm}^{-1}$ were assigned to the asymmetric stretching of $\mathrm{CO}_{3}^{-2}$ in the interlayer, indicating that some $\mathrm{CO}_{3}^{-2}$ ions existed in the gallery of HT $[23,24]$.The absorption at $548 \mathrm{~cm}^{-1}$ might be related to the lattice vibrations, such as $\mathrm{Mg}-\mathrm{O}-\mathrm{Al}$ or $\mathrm{O}-\mathrm{Mg}-\mathrm{O}$ vibration. This sample shows, the spectrum similar to that reported by[24]. The most remarkable difference amongst the peaks was at $3420 \mathrm{~cm}^{-1}$ representing hydroxyl $(\mathrm{OH})$ stretching. After the HT was loaded with $\mathrm{Fe}$ and $\mathrm{Mn}$, some differences in the locations of the absorbance peaks were observed. The band shifted and peak intensity decreased. The reduction of the $\mathrm{OH}^{-}$ group suggests that the water molecules in the gallery have been replaced with Fe and Mn ions. As described by [25] , this is a surface complexation mechanism where the chemical or electrostatic binding reaction between the metal ions and the functional groups occurs

The FTIR analysis of modified bentonite was also carried out to identify the functional groups as seen in Table 2 and the change in transmittance was observed in figure 5 .

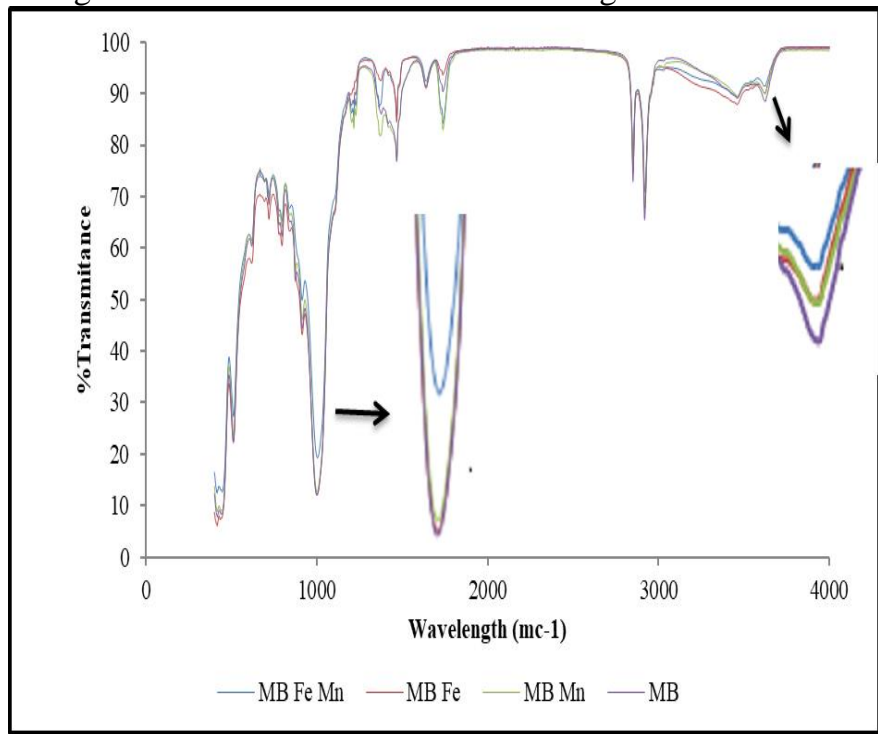

Fig. 5: FTIR for modified bentonite before adsorption and after adsorption of $\mathrm{Fe}$ with $\mathrm{Mn}$, adsorption of $\mathrm{Fe}$ and adsorption of $\mathrm{Mn}$ The examination of the FTIR spectra (4000-400 $\mathrm{cm}^{-1}$ ) provides information on fundamental vibrational modes of the constituent units of these materials. MB shows the FTIR pattern for MB (before adsorption), MB FeMn shows the FTIR pattern after the adsorption of $\mathrm{Fe}(\mathrm{II})$ and $\mathrm{Mn}(\mathrm{II}), \mathrm{MB}$ Fe shows the FTIR after the adsorption of Fe(II) and MB Mn shows the FTIR after the adsorption of $\mathrm{Mn}(\mathrm{II}), \mathrm{OH}$ stretching and bending vibrations occur in the spectral region of 3750-3500 and 950$600 \mathrm{~cm}^{-1}$, respectively. $\mathrm{Si}-\mathrm{O}$ and $\mathrm{Al}-\mathrm{O}$ stretching modes are found in the $1200-700 \mathrm{~cm}^{-1}$ range, while $\mathrm{Si}-\mathrm{O}$ and $\mathrm{Al}-\mathrm{O}$ bending modes dominate the $600-400 \mathrm{~cm}^{-1}$ region[26].

TABLE II: FUNCTIONAL GROUPS FOUND IN MODIFIED BENTONITE AT DIFFERENT WAVELENGTH

\begin{tabular}{ll}
\hline Functional group & Wavelength $\mathrm{cm}^{-1}$ \\
\hline $\mathrm{O}-\mathrm{H}$ for Al-OH, Si-OH & 3628 \\
C-H stretching & 2920 \\
C-H stretching & 2850 \\
H-O-H bending of water & 1633 \\
C-H stretching & 1470 \\
Si-O stretching & 1000 \\
OH deformation, linked to $\mathrm{Al}^{3}, \mathrm{Mg}^{2-}$ & 800 \\
Fe-O, Fe $\mathrm{O}_{3}$ Si-O-Al stretching & 510 \\
Si-O-Si bending & 420 \\
\hline
\end{tabular}

Table 2 shows the list of functional groups that were found in modified bentonite. Slight changes in intensities after adsorption were observed in the corresponding vibration absorption bands of the reactive functional groups as shown in Figure 5. The FTIR spectra showed that the aluminol and 
silanol groups are major sites for binding of metals to MB. Similar functional group were found in alkaline-modified montmorillonite by [27] and the adsorbent was proven to be efficient for the removal of $\mathrm{Mn}$ (II) and $\mathrm{Ni}(\mathrm{II})$.

\section{BET Analysis}

Surface area and pore size of adsorbents are among the important parameters that describe the quality of adsorbents as they affect directly their analyte retention abilities[28]. Bentonite clay can have the inter-lamellar expanded and the insertion of larger organic cations increasing the spacing between the tetrahedral sheets. This behavior may lead to an increase or decrease in surface area, depending on the arrangement, and thus the packing, of organic cations in the space among the alumina-silicate sheets. Obviously, larger surfactant cations may lead to compact packing in the inter-lamellar layer and result in more serious pore blocking that inhibits the passage of nitrogen molecules during BET analysis[29].

TABLE III: SURFACE PROPERTIES OF HYDROTALCITE AND MODIFIED BENTONITE ANALYZED BY BET

\begin{tabular}{|c|c|c|c|}
\hline Adsorbent & Surface Area $\left(\mathrm{m}^{2} / \mathrm{g}\right)$ & Pore size $(\AA)$ & Pore volume $\left(\mathrm{cm}^{3} / \mathrm{g}\right)$ \\
\hline MB before ads. & 3.13 & 508.6 & 0.036 \\
\hline MB after Mn ads. & 4.93 & 275.6 & 0.029 \\
\hline MB after Fe ads. & 8.55 & 168.5 & 0.041 \\
\hline MB after Fe+Mn ads. & 7.87 & 184.5 & 0.041 \\
\hline HT before ads. & 44.71 & 647.4 & 0.72 \\
\hline HT after Mn ads. & 25.29 & 145.9 & 0.11 \\
\hline HT after Fe ads. & 21.61 & 189.6 & 0.11 \\
\hline HT after Fe+Mn ads. & 24.25 & 173.2 & 0.11 \\
\hline
\end{tabular}

Table 3 shows that the specific surface areas for modified bentonite and hydrotalcite are $3.13 \mathrm{~m}^{2} / \mathrm{g}$, and $44.7 \mathrm{~m}^{2} / \mathrm{g}$, respectively as measured by the BET method. Normally the specific surface area of raw bentonite clay is $8.9 \mathrm{~m}^{2} / \mathrm{g}$. Results showed that the surface area of MB increase from $3.13 \mathrm{~m}^{2} / \mathrm{g}$ to $4.93 \mathrm{~m}^{2} / \mathrm{g}, 8.55 \mathrm{~m}^{2} / \mathrm{g}$ and $7.87 \mathrm{~m}^{2} / \mathrm{g}$ after the adsorption of $\mathrm{Mn}$, $\mathrm{Fe}$ and mixture of FE and Mn. This may be due to the fact that sulphuric acid was added into the solution and removed the impurities. It has been proven by [30] that the activation treatment using sulphuric acid can be used to increase the surface area of the adsorbent.

\section{CONCLUSION}

From the characterization results by FTIR, it was found that $\mathrm{HT}$ and MB contain functional groups that are generally responsible for surface complexation mechanism in adsorption. In addition, $\mathrm{HT}$ contains a $\mathrm{CO}_{3}{ }^{2-}$ FTIR peak which showed a slight decrease in intensity after the adsorption of Fe (II) and Mn (II) which may attribute to precipitation. Both MB and HT contain $\mathrm{Mg}^{2+}$ as analyzed by EDS which could be responsible for isomorphic substitution with $\mathrm{Fe}^{2+}$ and $\mathrm{Mn}^{2+}$ and it was shown from XRD results that isomorphic mechanism may have occurred. Through the analysis of the BET, HT had a high surface area than $\mathrm{MB}$ which may contribute to high adsorption capacity in HT than in MB. This finding agrees with theory [10] which specifies that the adsorption mechanisms of heavy metal ions involve precipitation, surface complexation, isomorphic substitution and chelation. Based on the characterization results, it can be concluded that both nano clays investigated may be used to remove heavy metals from acid mine drainage

\section{ACKNOWLEDGMENT}

Authors would like to thank National Research Foundation (NRF) and Durban University of Technology for the financial support and infrastructure.

\section{REFERENCES}

[1] Akcil, A. and S. Koldas, Acid Mine Drainage (AMD): causes, treatment and case studies. Journal of Cleaner Production, 2006. 14(12): p. $1139-1145$ https://doi.org/10.1016/j.jclepro.2004.09.006

[2] Diz, H.R., Chemical and biological treatment of acid mine drainage for the removal of heavy metals and acidity. 1997.

[3] Motsi, T., N. Rowson, and M. Simmons, Adsorption of heavy metals from acid mine drainage by natural zeolite. International Journal of Mineral Processing, 2009. 92(1): p. 42-48. https://doi.org/10.1016/j.minpro.2009.02.005

[4] Hallberg, K.B. and D.B. Johnson, Biological manganese removal from acid mine drainage in constructed wetlands and prototype bioreactors. Science of the Total Environment, 2005. 338(1): p. 115-124. https://doi.org/10.1016/j.scitotenv.2004.09.011

[5] Sheoran, A. and V. Sheoran, Heavy metal removal mechanism of acid mine drainage in wetlands: a critical review. Minerals engineering, 2006. 19(2): p. 105-116. https://doi.org/10.1016/j.mineng.2005.08.006

[6] Bhattacharyya, K.G. and S.G. Susmita, Kaolinite, montmorillonite, and their modified derivatives as adsorbents for removal of $\mathrm{Cu}$ (II) from aqueous solution Separation and Purification Technology, 2006. 50: p. 388-397. https://doi.org/10.1016/j.seppur.2005.12.014

[7] Adeyemo, A.A., I.O. Adeoye, and O.S. Bello, Adsorption of dyes using different types of clay: a review. Applied Water Science, 2017. 7(2): p. 543-568. https://doi.org/10.1007/s13201-015-0322-y

[8] Lianga, X., et al., Sorption of metal cations on layered double hydroxides. Physicochemical and Engineering Aspects, 2013. 433: p. 122- 131. https://doi.org/10.1016/j.colsurfa.2013.05.006

[9] Gong, J., et al., Efficient Removal of Heavy Metal Ions from Aqueous Systems with the Assembly of Anisotropic Layered Double Hydroxide Nanocrystals@Carbon Nanosphere. Environmental Science \& Technology, 2011. 45(14): p. 6181-6187. https://doi.org/10.1021/es200668q

[10] Liang, X., et al., Sorption of metal cations on layered double hydroxides. Colloids and surfaces A: physicochemical and engineering aspects, 2013. 433: p. 122-131. https://doi.org/10.1016/j.colsurfa.2013.05.006 
[11] Zubair, M., et al., Recent progress in layered double hydroxides (LDH)-containing hybrids as adsorbents for water remediation. Applied Clay Science, 2017. 143: p. 279-292. https://doi.org/10.1016/j.clay.2017.04.002

[12] Bradl, H.B., Adsorption of heavy metal ions on soils and soils constituents. Journal of Colloid and Interface Science, 2004. 277(1): p. $1-18$. https://doi.org/10.1016/j.jcis.2004.04.005

[13] Oyanedel-Craver, V.A., M. Fuller, and J.A. Smith, Simultaneous sorption of benzene and heavy metals onto two organoclays. Journal of Colloid and Interface Science, 2007. 309(2): p. 485-492. https://doi.org/10.1016/j.jcis.2006.10.001

[14] Yue, X., et al., Simultaneous removal of $\mathrm{Cu}$ (II) and $\mathrm{Cr}(\mathrm{VI})$ by $\mathrm{Mg}-\mathrm{Al}-\mathrm{Cl}$ layered double hydroxide and mechanism insight. Vol. 53. 2016. https://doi.org/10.1016/j.jes.2016.01.015

[15] Oyanedel-Craver, V.A. and J.A. Smith, Effect of quaternary ammonium cation loading and $\mathrm{pH}$ on heavy metal sorption to Ca bentonite and two organobentonites. Journal of Hazardous Materials, 2006. 137(2): p. $1102-1114$ https://doi.org/10.1016/j.jhazmat.2006.03.051

[16] Mishra, G., B. Dash, and S. Pandey, Layered double hydroxides: A brief review from fundamentals to application as evolving biomaterials. Applied Clay Science, 2018. 153: p. 172-186. https://doi.org/10.1016/j.clay.2017.12.021

[17] Rojas, R., Layered double hydroxides applications as sorbents for environmental remediation. 2012. 39-71.

[18] Lin, S.-H. and R.-S. Juang, Heavy metal removal from water by sorption using surfactant-modified montmorillonite. Journal of Hazardous Materials, 2002. 92(3): p. 315-326. https://doi.org/10.1016/S0304-3894(02)00026-2

[19] Lee, J., J. Choi, and J. Park, Simultaneous sorption of lead and chlorobenzene by organobentonite Chemosphere 2002. 49: p. 13091315. https://doi.org/10.1016/S0045-6535(02)00531-3

[20] Shekoohi, K., et al., Synthesis of some $\mathrm{Mg} / \mathrm{Co}-\mathrm{Al}$ type nano hydrotalcites and characterization. MethodsX, 2017. 4: p. 86-94. https://doi.org/10.1016/j.mex.2017.01.003

[21] Chi, L., et al., Crystalline/amorphous blend identification from cobalt adsorption by layered double hydroxides. Materials, 2018. 11(9): p. 1706. https://doi.org/10.3390/ma11091706

[22] Yue, X., et al., Simultaneous removal of $\mathrm{Cu}$ (II) and $\mathrm{Cr}$ (VI) by $\mathrm{Mg}-\mathrm{Al}-$ $\mathrm{Cl}$ layered double hydroxide and mechanism insight. Journal of Environmental Sciences, 2017. 53: p. 16-26. https://doi.org/10.1016/j.jes.2016.01.015

[23] Ramesh, S.T., et al., Kinetics and Equilibrium Studies for the Removal of Heavy Metals in Both Single and Binary Systems Using Hydroxyapatite. Vol. 2. 2012. 187-197. https://doi.org/10.1007/s13201-012-0036-3

[24] Zhao, D., et al., The adsorption of $\mathrm{Pb}$ (II) on $\mathrm{Mg} 2$ Al layered double hydroxide. Chemical Engineering Journal, 2011. 171(1): p. 167-174. https://doi.org/10.1016/j.cej.2011.03.082

[25] Ngah, W.W. and M. Hanafiah, Removal of heavy metal ions from wastewater by chemically modified plant wastes as adsorbents: a review. Bioresource technology, 2008. 99(10): p. 3935-3948. https://doi.org/10.1016/j.biortech.2007.06.011

[26] Eren, E. and B. Afsin, An investigation of $\mathrm{Cu}$ (II) adsorption by raw and acid-activated bentonite: A combined potentiometric, thermodynamic, XRD, IR, DTA study. Journal of Hazardous Materials, 2008. 151(2): p. 682-691. https://doi.org/10.1016/j.jhazmat.2007.06.040

[27] Akpomie, K.G. and F.A. Dawodu, Efficient abstraction of nickel(II) and manganese(II) ions from solution onto an alkaline-modified montmorillonite. Journal of Taibah University for Science, 2014. 8(4): p. 343-356. https://doi.org/10.1016/j.jtusci.2014.05.001

[28] Auta, M. and B.H. Hameed, Modified mesoporous clay adsorbent for adsorption isotherm and kinetics of methylene blue. Chemical Engineering Journal, 2012. 198-199: p. 219-227. https://doi.org/10.1016/j.cej.2012.05.075

[29] Wang, C., et al., Effect of exchange surfactant cations on the pore structure and adsorption charecteristics of montmorillonite. journal of colloid and interface science, 2004. 280(1): p. 27-35. https://doi.org/10.1016/j.jcis.2004.07.009
[30] Oliveira, R.N., et al., The increase of surface area of a Brazilian palygorskite clay activated with sulfuric acid solutions using a factorial design. Materials Research, 2013. 16: p. 924-928

https://doi.org/10.1590/S1516-14392013005000075 